\title{
Ethnic differences in stillbirth and early neonatal mortality in The Netherlands
}

\author{
A C J Ravelli, ${ }^{1}$ M Tromp, ${ }^{1}$ M Eskes, ${ }^{1}$ J C Droog, ${ }^{2}$ J A M van der Post, ${ }^{3} \mathrm{~K} J$ Jager, ${ }^{1}$ \\ B W Mol, ${ }^{3}$ J B Reitsma ${ }^{4}$
}

'Department of Medical

Informatics, Academic Medical Center (AMC), Amsterdam, The Netherlands

${ }^{2}$ Department of Obstetrics and Gynaecology, Leiden University Medical Center, Leiden, The Netherlands

${ }^{3}$ Department of Obstetrics and Gynaecology, AMC,

Amsterdam, The Netherlands ${ }^{4}$ Department of Clinical Epidemiology, Biostatistics and Bioinformatics, AMC, Amsterdam, The Netherlands

\section{Correspondence to}

Dr A C J Ravelli, Department of Medical Informatics, Academic Medical Center, PO Box 22700, 1100DE Amsterdam, The Netherlands;

a.c.ravelli@amc.uva.nl

Accepted 21 February 2010

Published Online First

18 August 2010

\section{ABSTRACT}

Background Ethnic disparities in perinatal mortality are well known. This study aimed to explore the contribution of demographic, socioeconomic, health behavioural and pre-existent medical risk factors among different ethnic groups on fetal and early neonatal mortality.

Methods We assessed perinatal mortality from 24.0 weeks' gestation onwards in 554234 singleton pregnancies of nulliparous women in the linked Netherlands Perinatal Registry over the period 2000-2006. Logistic regression modelling was used. Results Considerable ethnic differences in perinatal mortality exist especially in fetal mortality. Maternal age, socioeconomic status and pre-existent diseases could not explain these ethnic differences. Late booking visit could explain some differences. Compared with the Dutch, African women had an increased fetal mortality risk of OR 1.7 (95\% Cl 1.4 to 2.1); South Asian women, 1.8 (1.4 to 2.3); other non-Western women, 1.3 (1.1 to 1.6) and Turkish/Moroccan women, 1.3 (1.1 to 1.4$)$. The risk on early neonatal mortality was only increased in other non-Western women, OR 1.3 (1.0 to 1.8). Ethnic differences were even present in the women without risk factors including preterm births. Mortality risk for East Asian and other Western women was lower or comparable with the Dutch.

Conclusion Important ethnic differences in fetal mortality exist, especially among women of African and South Asian origin. Ethnic minorities should be more acquainted with the significance of early start of prenatal care. Tailored prenatal care for women with African and South Asian origin seems necessary. More research on underlying cause of deaths is needed by ethnic group.

\section{INTRODUCTION}

Ethnic disparities in perinatal mortality exist in Western countries. ${ }^{1-3}$ It has been argued that these differences are predominantly determined by socioeconomic disparities, although others state that biological and medical conditions underlay the elevated risks. ${ }^{4}$ These findings signify that differences in perinatal mortality between ethnic groups are poorly understood. ${ }^{2} 6-8$

In The Netherlands, $16 \%$ of pregnant women are from non-Western origin. The main ethnic minorities originate from the former Dutch colony Indonesia (independency in 1945), Surinam (independency in 1975), Turkey and Morocco as migrant labourers mainly in the 1960s. A recent study in The Netherlands showed that the non-Western women had a $40 \%$ higher risk of perinatal mortality. ${ }^{9}$ Previous studies showed that ethnicspecific differences exist in perinatal and infant mortality in The Netherlands. ${ }^{10-12}$ Ethnic women also experience an increased risk of severe maternal morbidity. ${ }^{13}$ It is unknown if ethnic differences exists in stillbirth on a national level.

The aim of this paper was to describe the differences in fetal and early neonatal mortality between women of different ethnic origin in The Netherlands. Furthermore, the aim was to explore the contribution of demographic, socioeconomic, health behavioural and pre-existent medical risk factors on fetal and early neonatal mortality among different ethnic groups.

\section{MATERIALS AND METHODS \\ Data sources}

The Netherlands Perinatal Registry (PRN) contains population-based information on pregnancies, deliveries and (re)admissions of newborns. ${ }^{14}$ The $\mathrm{PRN}$ is based on a validated probabilistic linkage of the national midwifery registry (LVR1), the obstetrics registry (LVR2) and the neonatology/ paediatrics registry (LNR). ${ }^{15} 16$ The recent linkage of 7 years of obstetric and neonatal registry data allows detailed analysis of a large cohort of 1.3 million births. ${ }^{17}$ The midwifery and obstetrics registries start at the first (booking) prenatal visit. If the child is admitted to a neonatal ward after birth, the information is collected in the neonatology registry. Around $96 \%$ of all births are included in the perinatal registration.

\section{Study population}

The study population comprised nulliparous women who gave birth to singletons during the period 2000-2006. We excluded births before the legal term of 24 weeks' gestation and below $500 \mathrm{~g}$ because there are terminations of pregnancy before 24 weeks that could be distributed unequally among the ethnic groups. ${ }^{9}$ Women who conceived after assisted reproductive technology ( $n=14766$, $2.6 \%$ ) were also excluded for reason of unequal distribution. The study population consisted of 554234 births including 3135 stillbirths and 1266 early neonatal deaths.

\section{Outcome variables}

Perinatal, fetal and early neonatal mortality were the main outcome variables. Fetal mortality (stillbirths) was defined as death of the unborn child either antenatal or during labour (per 1000 births). Early neonatal mortality was defined as death up to 7 days of life (per 1000 live births). Perinatal mortality is the sum of fetal and early neonatal mortality divided per 1000 births (including stillbirths) from 24 weeks' gestation onwards. Other 
adverse outcomes were preterm birth ( $<37.0$ weeks gestational age), low birth weight $(<2500 \mathrm{~g})$ and congenital anomalies.

\section{Definition of ethnicity}

The classification of ethnicity was performed by the healthcare professional on the basis of race and country of birth. Since the mid-1980s, this definition is used in the midwifery and obstetrics registry and is in fact a mixture of ethnicity and race. The Western ethnic groups included ethnic Dutch and other Western women with Caucasoid ancestry (Belgium, UK, Germany, etc). The non-Western ethnic group was classified in five subgroups. Two different ethnic groups originate from Surinam (a former Dutch colony): the African or Creole and the South Asian or Hindustani originating from Africa and India, respectively. The other subgroups include the Turkish/Moroccan women, the East-Asian women originating mainly from Indonesia (a former Dutch colony) and other non-Western women.

\section{Risk factors}

Demographic and socioeconomic risk factors were maternal age, urbanisation degree and socioeconomic status (SES). The urbanisation degree and SES indicators were created on the basis of the four-digit postcode of the pregnant woman. Urbanisation was based on the number of addresses per square kilometre and categorised in very urban ( $\geq 2500$ addresses $/ \mathrm{km}^{2}$ ), intermediate urban/rural (between 500 and 2500 addresses $/ \mathrm{km}^{2}$ ) and very rural $\left(<500\right.$ addresses $\left./ \mathrm{km}^{2}\right)$. The SES indicators included the data from The Netherlands Institute for Social Research/SCP in three categories (10th, 10-90, and $\geq 90$ th percentile), and the mean household equivalent income for neighbourhoods as low and high $(<40 \%, \geq 40 \%)$.

Pre-existent medical risk factors were essential hypertension, diabetes mellitus, other endocrine diseases, cardiac disease, systemic diseases, thrombo-embolic disorders and psychiatric disorders as recorded by the midwife or gynaecologist.

Behavioural risk factors considered were the booking visit and smoking during gestation. The timing of the first antenatal or booking visit was measured in weeks of gestational age and categorised in four groups as $<12$ weeks (in time), 12-17 weeks, after 18 weeks' gestational age (late) and unknown. Heavy smoking registered as "abuse of nicotine" was recorded by the healthcare professional based on self report of the women $(\geq 20$ cigarettes a day).

\section{Statistical analyses}

The prevalence of risk factors among the different ethnic groups was determined, and differences were tested with a $\chi^{2}$ test. The incidence of perinatal, fetal and early neonatal mortality, as well as preterm birth, low birth weight and congenital anomalies, was described for the different ethnic groups, and the differences were tested with a $\chi^{2}$ test.

The crude odds ratios (ORs) and the $95 \%$ confidence interval (95\% CI) of the fetal and neonatal mortality in the different ethnic groups were calculated using logistic regression modelling. The reference categories are based on that level of the predictor with the lowest risk of the outcome.

Table 1 Characteristics (per cent) of the 554234 pregnant nulliparous women by ethnic group

\begin{tabular}{|c|c|c|c|c|c|c|c|c|c|c|}
\hline Ethnic group & Dutch & $\begin{array}{l}\text { Other } \\
\text { Western }\end{array}$ & $\begin{array}{l}\text { Turkish/ } \\
\text { Moroccan }\end{array}$ & African & $\begin{array}{l}\text { South } \\
\text { Asian }\end{array}$ & $\begin{array}{l}\text { East } \\
\text { Asian }\end{array}$ & Other non-Western & Unknown & Total & $\chi^{2}, \mathrm{p}$ value \\
\hline Pregnant women, $\mathrm{n}$ & 460543 & 15007 & 34973 & 11605 & 5853 & 10675 & 12541 & 3037 & 554234 & \\
\hline Pregnant women (\%) & 83.1 & 2.7 & 6.3 & 2.1 & 1.1 & 1.9 & 2.3 & 0.5 & 100.0 & \\
\hline$<20$ & 2.3 & 4.3 & 7.7 & 19.9 & 6.7 & 7.4 & 10.9 & 6.0 & 3.5 & \\
\hline $20-24$ & 12.6 & 20.1 & 43.8 & 33.6 & 29.3 & 22.0 & 26.0 & 21.7 & 15.9 & \\
\hline $25-34$ & 74.2 & 62.4 & 43.6 & 40.9 & 56.7 & 59.4 & 52.9 & 63.7 & 70.2 & \\
\hline Mean & 29.1 & 28.5 & 25.2 & 24.6 & 26.7 & 27.8 & 26.9 & 27.6 & 28.6 & \\
\hline \multicolumn{11}{|l|}{ Urbanisation } \\
\hline Very urban & 17.0 & 35.9 & 48.7 & 55.3 & 55.1 & 33.6 & 41.6 & 32.4 & 21.7 & $<0.0001$ \\
\hline Urban/rural & 64.1 & 55.6 & 49.1 & 40.9 & 42.0 & 59.7 & 51.7 & 57.1 & 61.8 & \\
\hline Very rural & 18.9 & 8.5 & 2.2 & 3.9 & 3.0 & 6.7 & 6.7 & 10.5 & 16.5 & \\
\hline Low & 6.3 & 15.5 & 35.7 & 39.1 & 33.9 & 17.9 & 23.1 & 15.5 & 10.1 & \\
\hline Low income & 35.3 & 36.8 & 61.1 & 64.1 & 58.2 & 42.2 & 46.8 & 42.3 & 38.2 & $<0.0001$ \\
\hline Booking visit $\geq 18$ weeks & 13.2 & 23.0 & 20.4 & 32.7 & 22.8 & 24.0 & 28.4 & 17.4 & 15.0 & $<0.0001$ \\
\hline Heavy smoking & 0.6 & 0.4 & 0.3 & 0.2 & 0.1 & 0.2 & 0.1 & 0.4 & 0.4 & $<0.0001$ \\
\hline \multicolumn{11}{|l|}{ Pre-existent disease } \\
\hline Essential hypertension & 0.6 & 0.3 & 0.2 & 0.5 & 0.5 & 0.2 & 0.3 & 0.2 & 0.5 & $<0.0001$ \\
\hline Diabetes mellitus & 0.2 & 0.1 & 0.2 & 0.3 & 0.6 & 0.1 & 0.1 & 0.0 & 0.2 & $<0.0001$ \\
\hline Other endrocrinological diseases & 0.4 & 0.5 & 0.3 & 0.2 & 0.7 & 0.3 & 0.4 & 0.2 & 0.4 & $<0.0001$ \\
\hline Systemic disease & 0.1 & 0.1 & 0.1 & 0.1 & 0.1 & 0.1 & 0.1 & 0.0 & 0.1 & 0.03 \\
\hline
\end{tabular}


Table 2 Mortality and other adverse outcome by ethnic group

\begin{tabular}{|c|c|c|c|c|c|c|c|c|c|c|c|}
\hline Ethnic group & Dutch & $\begin{array}{l}\text { Other } \\
\text { Western }\end{array}$ & $\begin{array}{l}\text { Turkish/ } \\
\text { Moroccan }\end{array}$ & African & $\begin{array}{l}\text { South } \\
\text { Asian }\end{array}$ & $\begin{array}{l}\text { East } \\
\text { Asian }\end{array}$ & Other non-Western & Unknown & Total & Total & $\begin{array}{l}\chi^{2}, \\
\mathrm{p} \text {-value }\end{array}$ \\
\hline Number of births & 460543 & 15007 & 34973 & 11605 & 5853 & 10675 & 12541 & 3037 & & 554234 & \\
\hline Percentage (\%) & 83 & 3 & 6 & 2 & 1 & 2 & 2 & 1 & & & \\
\hline Fetal mortality per 1000 total births & 5.4 & 4.5 & 7.1 & 10.6 & 9.9 & 5.1 & 8.0 & 5.9 & 5.7 & 3135 & $<0.0001$ \\
\hline During gestation & 4.3 & 3.7 & 5.4 & 8.4 & 8.2 & 4.1 & 6.9 & 5.9 & 4.5 & 2508 & $<0.0001$ \\
\hline $\begin{array}{l}\text { Early neonatal mortality per } 1000 \text { live } \\
\text { births }\end{array}$ & 2.3 & 1.3 & 2.7 & 3.3 & 2.6 & 1.5 & 3.5 & 2.3 & 2.3 & 1266 & 0.0008 \\
\hline Within $24 \mathrm{~h}$ after birth & 1.3 & 0.7 & 1.8 & 2.4 & 1.6 & 0.9 & 2.5 & 1.3 & 1.3 & 742 & $<0.0001$ \\
\hline Early, days $1-6$ & 1.0 & 0.5 & 0.9 & 1.0 & 1.0 & 0.6 & 1.0 & 1.0 & 1.0 & 524 & 0.694 \\
\hline Preterm births (\%) & 7.8 & 6.3 & 5.6 & 8.9 & 9.5 & 6.1 & 7.2 & 4.8 & 7.6 & 42299 & $<0.0001$ \\
\hline
\end{tabular}

*No value because of low numbers.

The adjustment (enter method) included all relevant risk factors for mortality: maternal age, urbanisation, SES, low income, booking visit, heavy smoking and pre-existing diseases. The effect of each adjustment factor separately on ethnicity was also determined.

A second multivariate model was created, including the effect of preterm birth because preterm birth is more prevalent among African and South Asian women and is a strong indicator for mortality. Third, the analyses were repeated in the group of women with known ethnicity and without risk factors. For this group, the women with ages below 20 or above 40 years, low SES, low income level, booking visit $\geq 18$ weeks' gestation, heavy smoking, pre-existent diseases, gestational age below 32 weeks, congenital anomalies and birth weights below $2000 \mathrm{~g}$ were excluded. The SAS V.9.1 software was used (SAS Institute).

\section{RESULTS}

Table 1 shows the prevalence of risk factors for perinatal mortality among the different ethnic groups. The prevalence of teenage pregnancy was 10 times higher among the African women compared with the Dutch women (2.3\%). In addition, the African, South Asian, Turkish/Moroccan and other nonWestern women lived more often in very urban areas and had a lower social economic status compared with the Dutch women. The African and other non-Western women were more often late in care. On the contrary, heavy smoking was more prevalent in Dutch women. South Asian women more often had diabetes mellitus.

Perinatal mortality occurred in 7.9 per 1000 births, with significant ethnic differences (table 2). Fetal mortality was clearly higher in the African, South Asian, other non-Western and Turkish/Moroccan women compared with that in the Dutch women. Early neonatal mortality was increased among the African and other non-Western women, mainly caused by deaths within $24 \mathrm{~h}$ after birth (table 2).

The African and South Asian women also had the highest risks of preterm births and low birth weight. East Asian and other Western women and women of unknown ethnicity had

Table 3 Effects of ethnicity on fetal mortality and early neonatal mortality after adjustment for urbanisation or for booking visit

\begin{tabular}{|c|c|c|c|c|c|c|c|c|c|}
\hline Fetal mortality & Crude, & $95 \% \mathrm{C}$ & & \multicolumn{3}{|c|}{$\begin{array}{l}\text { Adjusted for urbanisation, } \\
\text { OR and } 95 \% \mathrm{CI}\end{array}$} & \multicolumn{3}{|c|}{$\begin{array}{l}\text { Adjusted for booking visit } \\
\mathrm{OR} \text { and } 95 \% \mathrm{CI}\end{array}$} \\
\hline \multicolumn{10}{|l|}{ Ethnicity } \\
\hline Dutch & 1.0 & Refere & & 1.0 & Refe & & 1.0 & Refe & \\
\hline Turkish/Moroccan & 1.3 & 1.2 & 1.5 & 1.4 & 1.2 & 1.6 & 1.3 & 1.1 & 1.4 \\
\hline African & 2.0 & 1.7 & 2.4 & 2.1 & 1.8 & 2.5 & 1.7 & 1.4 & 2.1 \\
\hline South Asian & 1.9 & 1.4 & 2.4 & 2.0 & 1.5 & 2.6 & 1.7 & 1.3 & 2.2 \\
\hline Unknown & 1.1 & 0.7 & 1.8 & 1.1 & 0.7 & 1.8 & 1.1 & 0.7 & 1.7 \\
\hline Early neonatal mortality & \multicolumn{3}{|c|}{ Crude, $\mathrm{OR}$ and $95 \% \mathrm{CI}$} & \multicolumn{3}{|c|}{$\begin{array}{l}\text { Adjusted for urbanisation } \\
\text { OR 95\% CI }\end{array}$} & \multicolumn{3}{|c|}{$\begin{array}{l}\text { Adjusted for booking visit } \\
\text { OR } 95 \% \mathrm{CI}\end{array}$} \\
\hline \multicolumn{10}{|l|}{ Ethnicity } \\
\hline Dutch & 1.0 & \multicolumn{2}{|c|}{ Reference } & 1.0 & \multicolumn{2}{|c|}{ Reference } & 1.0 & \multicolumn{2}{|c|}{ Reference } \\
\hline East Asian & 0.7 & 0.4 & 1.1 & 0.7 & 0.4 & 1.1 & 0.6 & 0.4 & 1.0 \\
\hline Other non Western & 1.5 & 1.1 & 2.1 & 1.6 & 1.2 & 2.2 & 1.3 & 1.0 & 1.8 \\
\hline Unknown & 1.0 & 0.5 & 2.2 & 1.1 & 0.5 & 2.2 & 1.0 & 0.5 & 2.1 \\
\hline
\end{tabular}


a mortality risk that was comparable or even lower than that in Dutch women (table 2).

A separate introduction of each risk factor to the model showed that adjustment for urbanisation increased the ethnic differences, and adjustment for booking visit after 18 weeks reduced the ethnic differences on both mortality outcomes (table 3). Separate adjustment for age, SES or pre-existent disease did not alter the ethnic differences on fetal and early neonatal mortality (data not shown).

Table 4 presents the crude and total adjusted ORs for different risk factors on fetal and early neonatal mortality. Compared with the Dutch women, the fetal mortality risks of both the African and South Asian women were 1.7 (95\% CI 1.4 to 2.1) and 1.8 (1.4 to 2.3), respectively. The risk for early neonatal mortality was only increased for other non-Western women 1.3 (95\% CI 1.0 to 1.8$)$.
The addition of preterm birth did not alter the increased fetal risk for the African and South Asian women, whereas the effects for Turkish-Moroccan and other non-Western women increased with OR 1.4 (1.2 to 1.6) and OR 1.5 (1.2 to 1.8), respectively (data not shown). The early neonatal mortality risk for the African (OR 1.4 (1.0 to 2.0)) women became significant, and the odds of other non-Western women (OR 1.5 (1.1 to 2.1)) increased (data not shown).

When the analysis was limited to the 264.502 (48\% of the study group) women without the risk factors, the ethnic differences became even higher. The risk on fetal mortality for the African and South Asian women were respectively OR 2.2 (1.1 to 4.0) and OR 2.3 (1.2 to 4.6) (table 5). In early neonatal mortality, the OR in the African women was increased to 3.1 (1.1 to 8.3). Additional adjustment for age did not change these effects.

Table 4 Crude and total adjusted ORs $(95 \% \mathrm{Cl})$ of risk factors for fetal and early neonatal mortality

\begin{tabular}{|c|c|c|c|c|c|c|c|c|c|c|c|c|}
\hline Risk factors & \multicolumn{3}{|c|}{$\begin{array}{l}\text { Fetal mortality crude, } \\
\mathrm{n}=3.135 / 554.234\end{array}$} & \multicolumn{3}{|c|}{$\begin{array}{l}\text { Total adjusted fetal } \\
\text { mortality** }\end{array}$} & \multicolumn{3}{|c|}{$\begin{array}{l}\text { Early neonatal mortality } \\
\text { crude, } n=1.266 / 551.099\end{array}$} & \multicolumn{3}{|c|}{$\begin{array}{l}\text { Total adjusted early } \\
\text { neonatal mortality* }\end{array}$} \\
\hline \multicolumn{13}{|l|}{ Ethnicity } \\
\hline Other Western & 0.8 & 0.7 & 1.1 & 0.8 & 0.6 & 1.0 & 0.6 & 0.4 & 0.9 & 0.5 & 0.3 & 0.8 \\
\hline Turkish/Moroccan & 1.3 & 1.2 & 1.5 & 1.3 & 1.1 & 1.4 & 1.2 & 1.0 & 1.5 & 1.1 & 0.9 & 1.4 \\
\hline African & 2.0 & 1.7 & 2.4 & 1.7 & 1.4 & 2.1 & 1.5 & 1.1 & 2.0 & 1.2 & 0.9 & 1.7 \\
\hline Other non Western & 1.5 & 1.2 & 1.8 & 1.3 & 1.1 & 1.6 & 1.5 & 1.1 & 2.1 & 1.3 & 1.0 & 1.8 \\
\hline Unknown & 1.1 & 0.7 & 1.8 & 1.1 & 0.7 & 1.7 & 1.0 & 0.5 & 2.2 & 1.0 & 0.5 & 2.1 \\
\hline \multicolumn{13}{|l|}{ Age (years) } \\
\hline$<20$ & 1.5 & 1.2 & 1.7 & 1.1 & 0.9 & 1.3 & 1.6 & 1.3 & 2.1 & 1.3 & 1.0 & 1.7 \\
\hline $20-24$ & 1.3 & 1.2 & 1.4 & 1.1 & 1.0 & 1.2 & 1.2 & 1.0 & 1.4 & 1.1 & 0.9 & 1.3 \\
\hline \multicolumn{13}{|l|}{ Urbanisation } \\
\hline Very urban & 1.0 & 0.9 & 1.1 & 0.8 & 0.7 & 0.9 & 0.9 & 0.8 & 1.1 & 0.9 & 0.7 & 1.0 \\
\hline Urban/rural & 1.0 & Refe & & 1.0 & Refe & & 1.0 & Refe & & 1.0 & Refe & \\
\hline Very rural & 1.1 & 0.9 & 1.1 & 1.0 & 0.9 & 1.1 & 1.1 & 0.9 & 1.3 & 1.1 & 0.9 & 1.2 \\
\hline \multicolumn{13}{|l|}{ SES } \\
\hline High & 1.0 & Refe & & 1.0 & Refe & & 1.0 & Refe & & 1.0 & Refe & \\
\hline Middle & 1.3 & 1.2 & 1.5 & 1.3 & 1.1 & 1.5 & 1.2 & 1.0 & 1.4 & 1.2 & 0.9 & 1.4 \\
\hline Low & 1.6 & 1.4 & 1.9 & 1.4 & 1.2 & 1.7 & 1.2 & 1.0 & 1.6 & 1.2 & 0.9 & 1.7 \\
\hline Low income & 1.2 & 1.1 & 1.3 & 1.1 & 1.0 & 1.2 & 1.0 & 0.9 & 1.2 & 1.0 & 0.8 & 1.1 \\
\hline \multicolumn{13}{|l|}{ Booking visit (weeks) } \\
\hline \multicolumn{13}{|l|}{ Pre-existent disease } \\
\hline $\begin{array}{l}\text { Essential } \\
\text { hypertension }\end{array}$ & 1.9 & 1.3 & 2.7 & 1.8 & 1.3 & 2.6 & 2.0 & 1.1 & 3.4 & 1.9 & 1.1 & 3.3 \\
\hline Diabetes mellitus & 2.9 & 1.7 & 4.9 & 2.7 & 1.6 & 4.5 & 2.6 & 1.1 & 6.2 & 2.4 & 1.0 & 5.9 \\
\hline Cardiac disease & 1.6 & 0.7 & 3.5 & 1.5 & 0.7 & 3.4 & 3.2 & 1.3 & 7.8 & 3.2 & 1.3 & 7.8 \\
\hline $\begin{array}{l}\text { Trombo-embolitical } \\
\text { disorders }\end{array}$ & 2.3 & 1.4 & 3.7 & 2.2 & 1.4 & 3.4 & 1.4 & 0.5 & 3.7 & 1.3 & 0.5 & 3.6 \\
\hline Psychiatric disorders & 1.7 & 1.1 & 2.8 & 1.5 & 0.9 & 2.5 & 0.8 & 0.2 & 2.3 & 0.7 & 0.2 & 2.1 \\
\hline
\end{tabular}

*Total adjusted for age, urbanisation, SES, low income, booking visit, smoking and pre-existent diseases. 
Table 5 Crude ORs (95\% Cl) for ethnicity on fetal and early neonatal mortality for 264502 women without risk factors

\begin{tabular}{lllllll}
\hline & \multicolumn{3}{c}{ Crude fetal mortality } & \multicolumn{3}{c}{$\begin{array}{l}\text { Crude early } \\
\text { neonatal mortality }\end{array}$} \\
\hline Ethnicity & \multicolumn{3}{l}{ Reference } & 1.0 & Reference \\
$\quad$ Dutch & 1.0 & 0.5 & 1.5 & 1.2 & 0.5 & 3.0 \\
Other Western & 0.8 & 0.5 & 1.7 & 1.2 & 0.6 & 2.6 \\
Turkish/Moroccan & 1.4 & 0.8 & 1.7 & \\
African & 2.2 & 1.1 & 4.0 & 3.1 & 1.1 & 8.3 \\
South Asian & 2.3 & 1.1 & 4.6 & $*$ & & \\
East Asian & 0.9 & 0.4 & 1.7 & $*$ & & \\
Other non Western & 0.8 & 0.4 & 1.6 & $*$ & & \\
\hline
\end{tabular}

Women aged $<20$ or $>40$ years, low SES, low income level, booking visit $\geq 18$ weeks' gestation, heavy smoking, pre-existent diseases, gestational age $<32$ weeks, congenital anomalies and a birth weight $<2000 \mathrm{~g}$ were excluded.

${ }^{*}$ No value because of low numbers.

\section{COMMENTS \\ Principal findings}

Important ethnic differences exist in stillbirth and early neonatal mortality among nulliparous women in The Netherlands, especially among African, South Asian and other non-Western women. Teenage pregnancy, living in very urban areas, lower social economic status and late in care were more prevalent among all the non-Western ethnic groups. Moreover, South Asian women had diabetes mellitus more often. These ethnic differences were more pronounced in fetal mortality risk. Living in urban areas, which was slightly protective; maternal age; SES and pre-existent medical conditions showed no effect on ethnic differences in mortality. Booking visit after 18 weeks' gestation explained partly the ethnic differences in mortality. The ethnic differences in mortality became even more visible in women without these risk factors. The women from other Western or East Asian origin have lower fetal and neonatal mortality risk compared with the Dutch women.

\section{Strengths and weaknesses of the study}

The nearly complete coverage of all births makes the large linked national perinatal database suitable for analysing the effect of different ethnic groups on both fetal and neonatal mortality. A study limitation is the definition of ethnicity, which is based on the information from the healthcare providers. Turkish and Moroccan women are from different ethnic origin but are registered in one group. The information of the ethnic origin of the father was not recorded, and possibly, some African women were defined as other non-Western. Another limitation of this study is the possible insufficient adjustment for SES because it was measured on postcode area; an effect of SES could be present if measured on the individual level. Underreporting by the healthcare providers of maternal pre-existing risks factors and especially of heavy smoking during pregnancy could also have affected the results; however, we have no reason to assume that underreporting is related to ethnicity of the women. Women with unknown ethnicity had comparable mortality risks as the Dutch women. The percentage of missing values of outcomes and risk factors did not differ between the ethnic groups and was overall below $2 \%$. The $4 \%$ missing birth data in the registry are due to non-reporting midwives and general practitioners (low-risk pregnancies), whereas $99 \%$ of the obstetricians participate in the registry.

The perinatal registry does not contain information on maternal education, body mass index, marital/relationship status and more detailed information about utilisation of healthcare, which might explain the ethnic differences found. Since 2009, this information and the country of both parents are included in the revised national perinatal registry. In this study, only nulliparous women were included, but the ethnic differences are also visible in the total population from 22 weeks onwards, including multiple births and pregnancies conceived after assisted reproductive technology. ${ }^{9}$

\section{Relation to other studies}

The finding of elevated perinatal mortality among ethnic minorities is in accordance with earlier international studies. ${ }^{3} 8$ In the UK, effects on perinatal mortality for African and South Asian women compared with white women were also found, where black women had the largest risks. ${ }^{1}$ The increased risk of neonatal mortality in African women in the first month of life and total infant mortality were also seen in the USA. ${ }^{2}$ No elevated risk in the East Asian women compared with the white women was reported in Norway. ${ }^{18}$

The finding on ethnic differences in fetal mortality is new. In previous studies in Europe, the differentiation of perinatal mortality in fetal and early neonatal mortality lacks on a national level. Increased perinatal mortality differences among ethnic minorities was found in other studies. ${ }^{10} 111920$ The healthy migrant effect is a well-known phenomenon, and this might explain the low fetal and early neonatal mortality in other Western and East Asian women compared with the Dutch women. The higher prevalence of teenaged pregnancy among non-Western women is reported as explanation for the elevated perinatal mortality risk. ${ }^{21}$ Our study does not confirm this. The crude mortality risk for teenaged African women was even lower than the mortality risk for older African women (data not shown), which was also shown in black newborns in the USA. ${ }^{2}$ This possibly suggests earlier maturation for procreation of women of African descent. Living in a very urban or rural area has been reported as a risk factor for perinatal mortality. However, we found that living in very urban areas was favourable for non-Western women. Perhaps, the easier access (travel distance) and a more adapted healthcare services to non-Western groups in urban areas plays a role. ${ }^{22}$ The high prevalence of low SES in non-Western women is another frequently used explanation of the elevated risks among these groups. ${ }^{23}{ }^{24}$ Although low SES is related to higher mortality rate, we did not find that low SES explained the elevated mortality risks among the non-Western women as was also found in Denmark. ${ }^{3}$

In The Netherlands, there is guaranteed access to maternity care at all levels as part of the national healthcare system, but this opportunity is possibly not fully taken by women from non-Western origin through possible language, cultural or knowledge barriers. In Norway, an audit of stillbirths revealed a strong association of suboptimal obstetric care in nonWestern women compared with Western women. ${ }^{25}$ This can be reason of late start of antenatal care and not alarming a care giver in time, less compliance to treatment or advise and, possibly, reticent policy of caregivers. ${ }^{26}{ }^{27}$ We found on average that $15 \%$ of the pregnant women started prenatal care after 18 weeks, whereas among African and other non-Western women, these percentages were doubled. However, in our study, the ethnic differences in mortality were also visible in the earlier starters as was also shown in the USA. ${ }^{28}$ Language problems are less obvious in the African and South Asian women who both came from Surinam, a former Dutch colony. Women with pre-existing diseases are at elevated risk for perinatal mortality; however, adjusting for or even excluding women with pre-existing diseases did not change the ethnic differences on fetal and neonatal mortality. 


\section{What is already known on this topic}

Ethnic minority women have higher perinatal mortality in Western countries.

- Teenage pregnancy, low SES and pre-existent diseases are important risk factors for perinatal mortality.

- Women from non-Western ethnic origin have more preterm births and low-birth-weight newborns.

\section{What this study adds}

- Ethnic differences in fetal and early neonatal mortality exist in The Netherlands, and fetal mortality is especially elevated among women of African, South Asian and other non-Western origin.

- Women from other Western or East Asian origin have lower fetal and neonatal mortality risk compared with the Dutch women.

- Living in urbanised areas diminishes the risk on mortality for ethnic minorities, and first booking visit after 18 weeks aggravates the risk on mortality. Maternal age, SES and preexistent disease had no effect.

- In women without risk factors, the ethnic risk differences in mortality were even more pronounced.

\section{Meaning of the study, questions and proposals}

The ethnic differences apparent especially in fetal mortality are remarkable. Our study revealed that excess in perinatal mortality among African, South Asian and other non-Western women could not be explained by the generally supposed explaining risk factors (teenage pregnancy, living in very urban areas and low SES). A possible explanation is that cultural or knowledge barriers affect the access of women to regular care or affect its effectiveness once women got access to care. Another possibility is a biological working mechanism. It could be relevant, for example, to evaluate if the optimum duration of pregnancy in the African, South Asian and other non-Western women is different from the Dutch women. ${ }^{1}$ The need for tailored perinatal care for women from African and South Asian ethnic background in case of preconception care, screening and risk factor management should be the focus of research. Because there are ethnic differences in fetal and neonatal mortality in The Netherlands, it should be stressed to record race/ethnicity of the patient because of its potential implications for decision-based care paths. ${ }^{29}$

Acknowledgements The authors thank all the Dutch midwives, obstetricians, neonatologist and other perinatal healthcare providers for the registration of perinatal information. They also thank the Foundation of the Netherland Perinatal Registry (http://www.perinatreg.nl) for the permission of using the registry data. In the PRN registry, the LVR1, LVR2 and LNR registries from the Royal Dutch Midwifery Organization, the Dutch Association for Obstetrics and Gynaecology and the Paediatric Association of The Netherlands are combined to one perinatal database.

\section{Competing interests None.}

Ethical approval The Dutch Perinatal Registry has given permission for the analysis of the data. Anonymous registry data: no ethical approval needed.

Contributors ACJR, MT, ME, BM and JBR contributed to the conception and the design of the study. JCD and JAMP were involved in the acquisition of the data. ACJR conducted the analyses, and ACJR and ME drafted the manuscript. All the authors had full access to of the reports and tables. All the authors provided advice on the analysis and the interpretation of the data. All the authors critically revised the draft versions and approved the final version of the manuscript.

Provenance and peer review Not commissioned; externally peer reviewed.

\section{REFERENCES}

1. Balchin I, Whittaker JC, Patel RR, et al. Racial variation in the association between gestational age and perinatal mortality: prospective study. BMJ 2007;334:833

2. Hessol NA, Fuentes-Afflick E. Ethnic differences in neonatal and postneonata mortality. Pediatrics 2005;115:e44-51.

3. Villadsen SF, Mortensen LH, Andersen AM. Ethnic disparity in stillbirth and infant mortality in Denmark 1981-2003. J Epidemiol Community Health 2009;63:106-12.

4. Balchin I, Steer PJ. Race, prematurity and immaturity. Early Hum Dev 2007;83:749-54

5. Troe EJ, Kunst AE, Bos V, et al. The effect of age at immigration and generational status of the mother on infant mortality in ethnic minority populations in The Netherlands. Eur J Public Health 2007;17:134-8.

6. Gould JB, Madan A, Qin C, et al. Perinatal outcomes in two dissimilar immigrant populations in the United States: a dual epidemiologic paradox. Pediatrics 2003;111 e676-82.

7. Zeitlin J, Combier E, De CF, et al. Socio-demographic risk factors for perinatal mortality. A study of perinatal mortality in the French district of Seine-Saint-Denis. Acta Obstet Gynecol Scand 1998;77:826-35.

8. Gissler M, Alexander S, Macfarlane A, et al. Stillbirths and infant deaths among migrants in industrialized countries. Acta Obstet Gynecol Scand 2009;88:1-15.

9. Ravelli AC, Tromp M, van Huis MM, et al. Decreasing perinatal mortality in The Netherlands, 2000-2006: a record linkage study. J Epidemiol Community Health 2009;63:761-5.

10. van Enk A, Buitendijk SE, van der Pal KM, et al. Perinatal death in ethnic minorities in The Netherlands. J Epidemiol Community Health 1998;52:735-9.

11. Schulpen TW, van Steenbergen JE, van Driel HF. Influences of ethnicity on perinatal and child mortality in The Netherlands. Arch Dis Child 2001;84:222-6.

12. Troe EJ, Bos V, Deerenberg IM, et al. Ethnic differences in total and cause-specific infant mortality in The Netherlands. Paediatr Perinat Epidemiol 2006;20:140-7.

13. Zwart JJ, Richters JM, Ory F, et al. Severe maternal morbidity during pregnancy, delivery and puerperium in The Netherlands: a nationwide population-based study of 371,000 pregnancies. BJOG 2008;115:842-50.

14. Stichting Perinatale Registratie Nederland. Perinatal Care in The Netherlands 2006. Utrecht: Stichting Perinatale Registratie Nederland, 2008.

15. Meray N, Reitsma JB, Ravelli AC, et al. Probabilistic record linkage is a valid and transparent tool to combine databases without a patient identification number. J Clin Epidemiol 2007;60:883-91.

16. Tromp M, Ravelli AC, Meray N, et al. An efficient validation method of probabilistic record linkage including readmissions and twins. Methods Inf Med 2008;47:356-63.

17. Ravelli ACJ, Eskes M, Tromp M, et al. Perinatal mortality in The Netherlands 2000-2006: risk factors and risk selection (In Dutch). Ned Tijdschr Geneeskd 2008;152:2728-33

18. Vangen S, Stoltenberg C, Skjaerven R, et al. The heavier the better? Birthweight and perinatal mortality in different ethnic groups. Int J Epidemiol 2002;31:654-60.

19. Lumey LH, Reijneveld SA. Perinatal mortality in a first generation immigrant population and its relation to unemployment in The Netherlands. J Epidemiol Community Health 1996;50:228.

20. Alderliesten ME, Stronks K, van Lith JM, et al. Ethnic differences in perinatal mortality. A perinatal audit on the role of substandard care. Eur J Obstet Gynecol Reprod Biol 2008;138:164-70.

21. Garssen J, van der Meulen A. Perinatal mortality in The Netherlands backgrounds on worsening international ranking. Demogr Res 2004;11:357-94.

22. Larson EH, Hart LG, Rosenblatt RA. Is non-metropolitan residence a risk factor for poor birth outcome in the U.S.? Soc Sci Med 1997;45:171-88.

23. Kramer MS, Seguin L, Lydon J, et al. Socio-economic disparities in pregnancy outcome: why do the poor fare so poorly? Paediatr Perinat Epidemiol 2000;14:194-210.

24. Bos V, Kunst AE, Garssen J, et al. Socioeconomic inequalities in mortality within ethnic groups in The Netherlands, 1995-2000. J Epidemiol Community Health 2005:59:329-35

25. Saastad E, Vangen S, Froen JF. Suboptimal care in stillbirths - a retrospective audit study. Acta Obstet Gynecol Scand 2007:86:444-50.

26. Alderliesten $\mathbf{M}$, Vrijkotte $T$, van der WM, et al. Late start of antenatal care among ethnic minorities in a large cohort of pregnant women. BJOG 2007;114:1232-9.

27. Essen B, Bodker B, Sjoberg NO, et al. Are some perinatal deaths in immigrant groups linked to suboptimal perinatal care services? BJOG 2002;109:677-82.

28. Healy AJ, Malone FD, Sullivan LM, et al. Early access to prenatal care: implications for racial disparity in perinatal mortality. Obstet Gynecol 2006;107:625-31.

29. Agyemang C, Seeleman C, Suurmond J, et al. Racism in health and health care in Europe: where does The Netherlands stand? Eur J Public Health 2007:17:240-1. 